Review

\title{
The Genetic Variant of SARS-CoV-2: would It Matter for Controlling the Devastating Pandemic?
}

\author{
Shuxin Guo ${ }^{1,2}$, Kefang Liu² and Jun Zheng ${ }^{1,3 凶}$ \\ 1. Faculty of Health Sciences, University of Macau, Macau SAR, China \\ 2. Chinese Academy of Sciences Key Laboratory of Pathogenic Microbiology and Immunology, Institute of Microbiology, Chinese Academy of Sciences, \\ 100101 Beijing, China \\ 3. Institute of Translational Medicine, University of Macau, Macau SAR, China \\ $\bowtie$ Corresponding author: junzheng@um.edu.mo \\ (C) The author(s). This is an open access article distributed under the terms of the Creative Commons Attribution License (https://creativecommons.org/licenses/by/4.0/) \\ See http:/ /ivyspring.com/terms for full terms and conditions.
}

Received: 2021.02.07; Accepted: 2021.03.12; Published: 2021.04.10

\begin{abstract}
The pandemic of COVID-19, caused by severe acute respiratory syndrome coronavirus 2 (SARS-CoV-2), is far from being controlled despite the great effort that have been taken throughout the world. Herd immunity through vaccination is our major expectation to rein the virus. However, the emergence of widespread genetic variants could potentially undermine the vaccines. The evidence that some variants could evade immune responses elicited by vaccines and previous infection is growing. In this review, we summarized the current understanding on five notable genetic variants, i.e., D614G, Cluster 5, VOC 202012/01, 501Y.V2 and P.1, and discussed the potential impact of these variants on the virus transmission, pathogenesis and vaccine efficacy. We also highlight that mutations in the $\mathrm{N}$-terminal domain of spike protein should be considered when evaluating the antibody neutralization abilities. Among these genetic variants, a concern of genetic variant 501Y.V2 to escape the protection by vaccines was raised. We therefore call for new vaccines targeting this variant to be developed.
\end{abstract}

Key words: SARS-CoV-2, COVID-19, Genetic variant, D614G, VOC 202012/01, 501Y.V2

\section{Introduction}

Coronavirus Disease 2019 (COVID-19), caused by severe acute respiratory syndrome coronavirus 2 (SARS-CoV-2), has become an unprecedented challenge to globe since the $21^{\text {st }}$ century. This disease was initially emerged at the end of 2019 and the culprit was quickly identified as a novel coronavirus of SARS-COV-2 [1-4]. Being highly contagious and able to be transmitted by asymptomatic patients, SARS-COV-2 has quickly spread all over the world [1, 5, 6]. As of 5 March 2021, there are in total 115 million people have been infected, resulting in over 2.5 million deaths globally. The devastating pandemic has badly disrupted the normal social activities and economic growth. Many cities around the world have been locked down and numerous people were quarantined; travel around the world was also restricted.

Numerous efforts have been tried out since the outbreak of COVID-19 to find effective therapeutic drugs and preventative vaccines that could help the return of our society to pre-pandemic normalcy. Among many drug candidates with high expectations, remdesivir have finally received authorization by the US Food and Drug Administration for emergency use as a treatment for COVID-19 [7]. However, the therapeutic efficacy is still under debate $[8,9]$. Till today, there is no drug potentially being a sovereign remedy for COVID-19. High expectation is now given to the vaccines developed against SARS-CoV-2. So far, a great many vaccine candidates are being developed, among which ten vaccines have completed their phase 3 trials and being approved for clinical use [10-12]. However, virus evolution could undermine the COVID-19 vaccines. Despite the presence of a proofreading function in viral replication enables coronaviruses with lower rate of evolution compared to other RNA-viruses [13-15], genetic variants of SARS-CoV-2 
have emerged [16] and several such variants have caused global concerns on the protective efficacy of currently developed vaccines [17-19]. In this review, we will summarize the nature of five major genetic variants attracting public attention and discuss the potential impact of these variants as well as the mutations in N-terminal domain (NTD) of spike protein (S protein) on the control of the pandemic.

\section{A brief introduction on SARS-COV-2 and its $S$ protein}

SARS-CoV-2 is a single-strand, positive-sense RNA virus belonging to Beta-coronavirus genus $[1,5$, 20]. This genus also includes another two members known to infect human: severe acute respiratory syndrome coronavirus (SARS-CoV) and Middle East respiratory syndrome coronavirus (MERS-CoV), accountable for SARS (2002-2003) and MERS outbreaks respectively [21-24]. The genome sequence identity of SARS-CoV-2 is up to $79 \%$ comparing with SARS-CoV and 50\% with MERS-CoV [21]. Compared to SARS-CoV and MERS-CoV, SARS-CoV-2 is more infectious but demonstrates lower case fatality rates [1].

There are at least 12 open reading frames (ORFs) in the genome of SARS-CoV-2, named as ORF1, Spike (S), ORF3, Envelope (E), Matrix (M), ORF7, ORF8, ORF9, ORF10b, Nucleocapsid (N), ORF13 and ORF14 [21]. ORF1 occupied approximate $67 \%$ in the whole encoding gene and encodes 15 non-structural proteins. Remaining ORFs encode 4 structural proteins ( $\mathrm{S}$ protein, $\mathrm{E}$ protein, $\mathrm{M}$ protein and $\mathrm{N}$ protein) and accessory proteins [25].

Surface glycoproteins are the most important elements for many viruses that are required for specific binding of cellular receptors, membrane fusion, and virus entry into the host cell [20]. The epitopes of the surface glycoproteins are also recognized by neutralizing antibodies as part of an effective adaptive immune response. $S$ protein in SARS-CoV-2 is the most important glycoprotein on the virion surface and is the main protein used as a target in COVID-19 vaccines [20]. SARS-CoV-2 uses S protein to recognize and bind human angiotensin converting enzyme 2 (hACE2) on the surface of host cells $[26,27]$, and then enter host cells by endocytosis $[28,29]$. The $S$ protein is a trimer. Each of its monomer has 1273 amino acids and is composed of two function subunits named S1 and S2 subunits, which is cleaved initially by Furin and then by the Transmembrane Serine Protease 2 (TMPRSS2) [27, 30-32]. S1 contains a region that binds to receptors named receptor binding domain (RBD). S2 subunit is relatively conserved, helping membrane fusion during the virus infect cells (Fig. 1) [32, 33]. Since outbreak of COVID-19, numerous genetic mutations were observed in SARS-CoV-2 isolates [34]. The genetic variation in the SARS-CoV-2 surface glycoprotein is of paramount importance as the mutations are likely affect the vaccine effectiveness or immune escape of the virus.

\section{Important genetic variants of SARS-CoV-2}

\section{D614G variant}

The SARS-CoV-2 D614G variant, emerged at the end of January 2020, was first noticed in April 2020 in a preprint by Korber and colleagues, who warned of "D614G is increasing in frequency at an alarming rate" [35]. The variant of D614G harbors a substitution of aspartic acid by a glycine at the position 614 of the virus spike glycoprotein, which helps virus particles to penetrate cells (Table 1) [35, 36].

During the infection, $S$ protein of SARS-CoV-2 mediates the binding of the virus to ACE2 to gain cell entry [20, 32]. The mutation of D614G attracted considerable attention as such mutation potentially could alter the receptor binding affinity, thus the virus infectivity and the immunogenicity [37]. The importance of the D614G mutation was quickly seen by the analysis of the frequency of the ancestral strain D614 and D614G variant over time [35]. The studies found that the location initially reporting the D614 viruses in the pandemic were often dominated by D614G virus subsequently [35, 38, 39]. In addition, patients infected by the D614G variant demonstrated higher viral loads than that seen in the primary strain in the upper respiratory tract $[35,40]$.

It seems that variant D614G has enhanced abilities for infection and transmission [35, 39, 41-44]. Initial experimental study on the D614G was performed using pseudovirus. Vesicular stomatitis virus and lentiviral particles incorporating the D614G variant were used to study the replication kinetics, and D614G demonstrated significantly higher pseudovirus titers in multiple cell types [35, 41]. Subsequently, Planete and colleague engineered a D614G variant in the USA-WA1/2020 strain and used the resultant virus to infect human lung epithelial cells and the primary human airway tissue [42]. They found that the mutation D614G enhanced viral replication through increasing the infectivity and stability of virions [42]. In the Syrian golden hamster model, hamsters infected by D614G variant produced higher infectious titers in the nasal washes and the trachea, but not in the lungs, compared to those infected by D614 viruses [42]. A competition assay comparing virus of D614G and D614 recovered the virus D614G / D614 ratio of 1.2 to 2.6, suggesting that $\mathrm{D}$ substitution by $\mathrm{G}$ at residue 614 of the $S$ protein 
likely increases the virus fitness and transmission [42]. These findings were echoed by another group, who used similar approach and concluded that D614G variant enhanced SARS-COV-2 infectivity, competitive fitness, and transmission in primary human cells and animal model [44]. An enhanced entry of D614G was seen with pseudoviruses carrying D614G, which correlated with the observation of less S1 domain shedding and higher $S$ protein incorporation into the virion [43]. The enhanced transmissibility could also attribute to the increased stability of SARS-CoV-2 [42]. By comparing the decay of infectivity of D614 and D614G virus over time at $33^{\circ} \mathrm{C}, 37^{\circ} \mathrm{C}$ and $42^{\circ} \mathrm{C}$, the D614G variant retained higher infectivity at all temperatures than the D614 virus [42]. However, it is of note that the analysis of a dataset of 46,723 SARS-CoV-2 genomes isolated from patients worldwide did not find any evidence associate with significantly increased viral transmission of variant D614G [45].

A
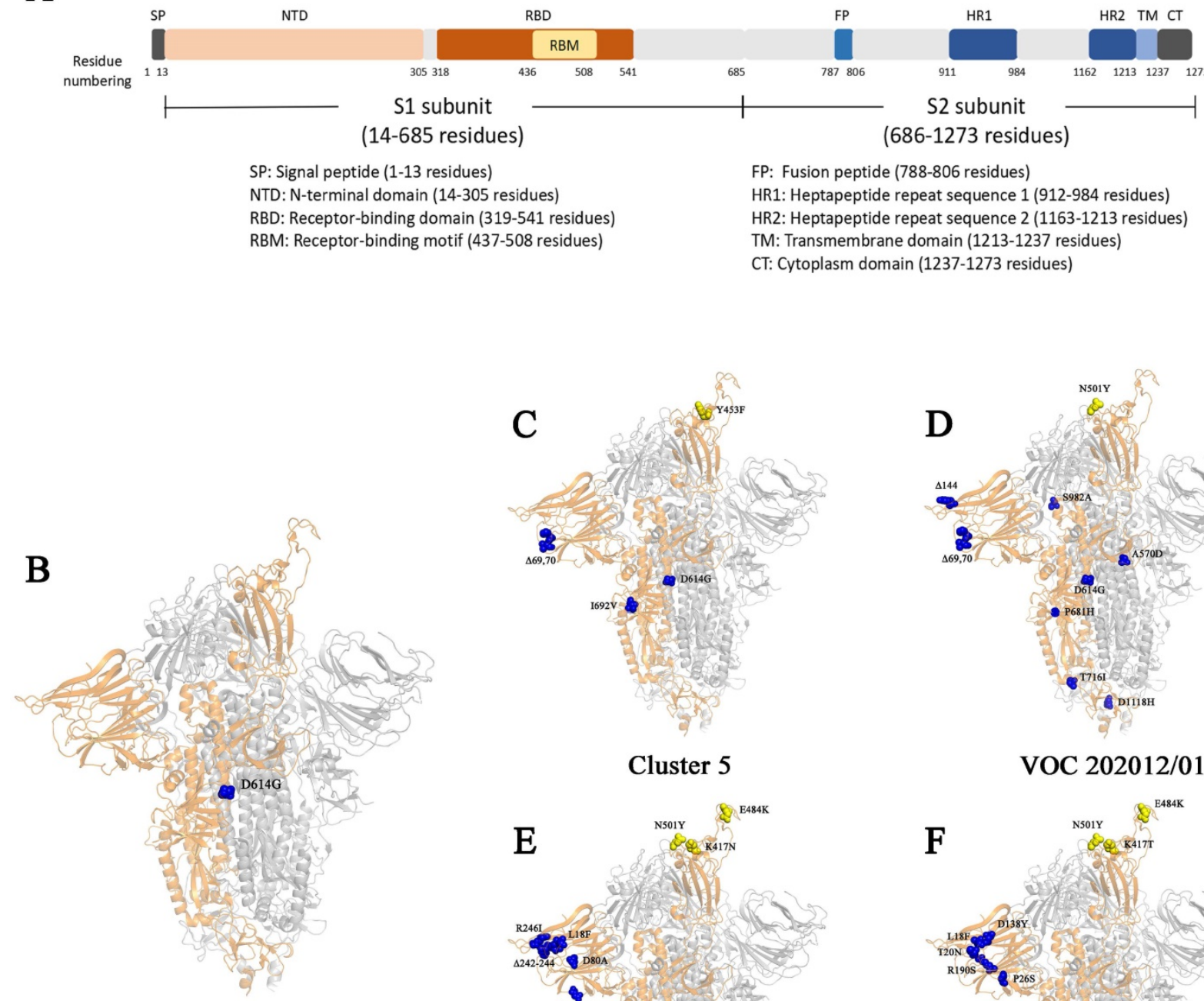

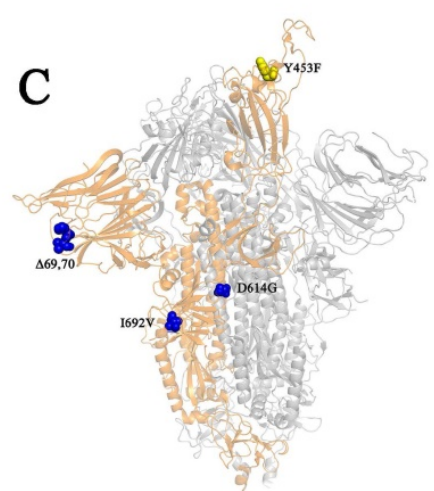

Cluster 5

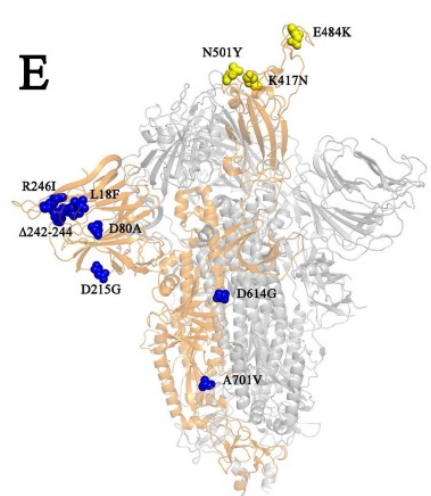

501Y.V2

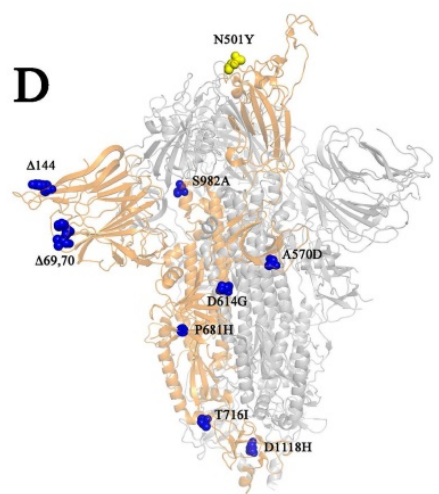

VOC 202012/01

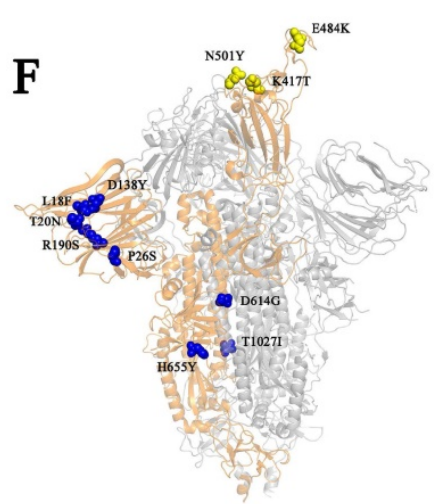

P.1

Fig. 1. The $S$ protein and its mutations in different genetic variants. (A) The schematic diagram of different domains in $S$ protein. (B-F) The structural demonstration of mutations on S protein (PBD:6zgg) [97] in genetic variant D614G (B), Cluster 5 (C), VOC202012/01 (D), 501 Y.V2 (E), and P.1 (F). The orange structure shows the monomer of spike protein; the yellow spheres represent the mutations on RBD; the blue spheres represent the mutations outside of RBD. 
Table 1. Summary of mutations on $\mathrm{S}$ proteins in the five SARS-CoV-2 variants

\begin{tabular}{|c|c|c|c|c|c|c|c|}
\hline \multirow{2}{*}{$\begin{array}{l}\text { Amino acid position in } \mathrm{S} \\
\text { protein }\end{array}$} & Wuhan-Hu-1 & D614G & Cluster 5 & VOC 202012/01 & 501Y.V2 & P.1 & \multirow[t]{2}{*}{ Note } \\
\hline & \multicolumn{6}{|c|}{ Residues in S protein } & \\
\hline 18 & $\mathrm{~L}$ & $*$ & * & * & $\mathrm{F}$ & $\mathrm{F}$ & NTD \\
\hline 20 & $\mathrm{~T}$ & $*$ & * & * & * & $\mathrm{N}$ & \\
\hline 26 & $\mathrm{P}$ & $*$ & * & * & * & $S$ & \\
\hline 69,70 & $\mathrm{H}, \mathrm{V}$ & $*$ & Delete & Delete & * & * & \\
\hline 80 & $\mathrm{D}$ & $*$ & * & * & A & * & \\
\hline 138 & $\mathrm{D}$ & $*$ & * & * & * & Y & \\
\hline 144 & $\mathrm{Y}$ & $*$ & * & Delete & * & * & \\
\hline 190 & $\mathrm{R}$ & $*$ & * & * & * & $\mathrm{S}$ & \\
\hline 215 & $\mathrm{D}$ & $*$ & * & * & G & * & \\
\hline $242-244$ & $\mathrm{~L}, \mathrm{~A}, \mathrm{~L}$ & * & * & * & Delete & * & \\
\hline 246 & $\mathrm{R}$ & $*$ & * & * & I & * & \\
\hline 417 & K & * & * & * & $\mathrm{N}$ & $\mathrm{T}$ & RBD \\
\hline 453 & Y & * & $\mathrm{F}$ & * & * & $*$ & \\
\hline 484 & $\mathrm{E}$ & $*$ & * & * & K & K & \\
\hline 501 & $\mathrm{~N}$ & $*$ & * & Y & Y & Y & \\
\hline 570 & A & $*$ & * & $\mathrm{D}$ & * & * & \\
\hline 614 & $\mathrm{D}$ & G & G & G & G & G & \\
\hline 655 & $\mathrm{H}$ & * & * & * & * & Y & \\
\hline 681 & $\mathrm{P}$ & $*$ & * & $\mathrm{H}$ & * & * & \\
\hline 692 & I & * & $\mathrm{V}$ & * & * & $*$ & \\
\hline 701 & A & $*$ & * & * & $\mathrm{V}$ & * & \\
\hline 716 & $\mathrm{~T}$ & * & * & I & * & $*$ & \\
\hline 982 & $S$ & $*$ & * & A & * & $*$ & Heptad repeat 1 \\
\hline 1027 & $\mathrm{~T}$ & $*$ & * & * & * & I & \\
\hline 1118 & $\mathrm{D}$ & * & * & $\mathrm{H}$ & * & $*$ & \\
\hline 1229 & M & $*$ & I & * & * & $*$ & Transmembrane domain \\
\hline
\end{tabular}

In contrast to the enhanced transmissibility, the mutation of D614G has little effect on the pathogenesis of SARS-CoV-2 in the hamster animal model [44]. Consistently, patient infected by D614G did not show any altered disease severity $[35,40]$. To accurately recapitulate the effect of D614G variant on the virus transmissibility and clinical severity, Volz et al. examined D614G variant using more than 25,000 whole genome SARS-CoV-2 sequences from COGUK dataset. They found that D614G was associated with higher viral load and younger age of patients [39]. However, no increased COVID-19 mortality or clinical severity was found to be correlated with D614G [39]. Interestingly, structural and functional analysis on D614G found that this mutation did not alter $\mathrm{S}$ protein synthesis, processing, or incorporation into SARS-CoV-2 particles, whereas the affinity of D614G to ACE2 was significantly reduced due to a faster dissociation rate [41]. Conversely, another group showed an enhanced binding of D614G variant to hACE2 [46].

Immunogenicity alteration is the most concern for the current efforts to control the pandemic by vaccination. Fortunately, the mutation in D614G variants seems not compromise the effectiveness of vaccines currently being developed against the ancestral SARS-COV-2. Kawaoka et al. used convalescent human serum and neutralizing antibodies to examine their blockage on live viruses of D614G variant and did not find any significant difference, consistent with the results from a separated study [37, 44]. However, Plante et al. demonstrated that sera from hamsters infected with D614 virus have modestly higher neutralization titers against D614G variant than that against D614 virus [42]. Consistently, Weissman and colleagues evaluated the neutralization of pseudoviruses bearing either D614 or D614G spike by sera from spike-immunized mice, non-human primates or convalescent sera from people infected with either form of the virus. They found that D614G was more susceptible to neutralization by all of the sera [47]. Mechanism study on the enhanced vulnerability to neutralization by a negative stain electron microscopy revealed that the D614G spike has a higher percentage of the 1-RBD "up" conformation, which likely increases the epitope exposure to antibodies [47].Taken together, these results suggested that D614G mutation is unlikely reduce the ability of current vaccines to protect against COVID-19.

It is of note that D614G mutation has dominated the COVID-19 pandemic now (Table 2) [48] and all the variants mentioned below (Cluster 5, VOC 202012/01, 501Y.V2 and P.1.) carry the D614G mutation (Table 1).

\section{Cluster 5}

In November 2020, the Danish public health authorities reported an outbreak of COVID-19 in North Jutland of Denmark that infected with mink-related virus variants (Table 2) [49]. A unique 
variant stood out in 12 human cases (from 7 to 79 years) that was subsequently named as cluster 5 , also called " $\Delta F V I " ~[49]$. In this variant, five mutations appeared on the $S$ protein, including: $\mathrm{Y} 453 \mathrm{~F}$, a H69/V70 deletion $(\Delta \mathrm{H} 69 / \Delta \mathrm{V} 70), \mathrm{I} 692 \mathrm{~V}, \mathrm{~S} 1147 \mathrm{~L}$ and M1229I [49]. The Y453F mutation locates in the RBD that directly contacts the host ACE2 at amino acid 34 [27]. The mutation I692V occurs seven amino acids downstream of the furin cleave site, whereas S1147L and M1229I locates on the S2 subunit (Table 1) [49]. In addition, the simultaneous mutations of $\Delta \mathrm{H} 69 / \Delta \mathrm{V} 70$ and $\mathrm{Y} 453 \mathrm{~F}$ were also found in several other variants closely related to cluster 5 with high frequency [49, 50].

Cluster 5 demonstrated an about 10-fold slower growth than SARS-CoV-2 wild type virus and several other variants isolated from patients at $24 \mathrm{~h}$ post inoculation of Vero E6 cells. However, a titer comparable to wild type but higher than other variants were seen at the time point from $24 \mathrm{~h}$ to 96 post inoculation [49]. This slower growth of cluster 5 before $24 \mathrm{~h}$ post inoculation suggests a potential failure of diagnosis in the early infection stage.

The immunogenicity of variant cluster 5 has been assessed to address the concerns on a potentially reduced recognition of the virus by antibodies elicited by SARS-CoV-2 infection or vaccination. The results showed that the mutations in cluster $5 \mathrm{might}$ moderately decrease sensitivity to neutralizing antibodies [49]. In this study, the convalescent plasma with different neutralization titers was tested against cluster 5 variant. It was found that sera with different neutralization titer of wild type virus showed distinguishing neutralizing ability against Cluster 5 . The neutralization activities of sera with high titers $(n=2)$ were not affected, whereas those of plasma with low $(n=4)$ and intermediate $(n=3)$ titers were lost. An average of 3.58-fold decrease in neutralization activities of all 9 samples was observed [49]. However, caution should be taken to interpret the results due to the small sample size.

Fortunately, following the strict measures by Denmark, the Cluster 5 seems already extinct (Table 2) [51]. However, vigilance should be given for the transmission route between mink and human. In fact, a similar transmission between mink and human, which was caused by distinct genetic variant from cluster 5, has also been occurred in Netherlands [52].

\section{VOC 202012/01}

The Variant of Concern (VOC) 202012/01 strain was originally derived from the SARS-CoV-2 20I/GR clade (also named as B.1.1.7 or 20I/501Y.V1), which emerged from South East England in September 2020 and has become the dominant strain in England in November/December 2020 (Table 2) [16, 53-55]. It has expanded to 94 countries (Table 3) [56]. The variant VOC 202012/01 bears 17 mutations, among which eight are located in the S protein: 6 substitutes and 2 deletions on $\mathrm{S}$ protein, 4 mutations on ORF1ab protein, 3 mutations on ORF8 protein and 2 mutations on $\mathrm{N}$ protein [57]. Detailed information of mutations in VOC 202012/01 was shown in Table 1. The high number of novel mutations suggests that this variant might evolve from a single individual in a long-time infection, or from a geographic region with very poor sampling [58]. Three mutations, namely N501Y, $\Delta \mathrm{H} 69 / \Delta \mathrm{V} 70$ and $\mathrm{P} 681 \mathrm{H}$, locate in $\mathrm{S}$ protein. Residue N501 of $S$ protein is one of the six critical amino acids interacting with ACE2 receptor [59]. Mutant N501Y has demonstrated significant increase in the binding affinity to ACE2 [60-62]. $\Delta \mathrm{H} 69 / \Delta \mathrm{V} 70$ has been circulating, separately and independently, or in other variant (such as in Cluster 5) for long [58]. The mutation of $\Delta \mathrm{H} 69 / \Delta \mathrm{V} 70$ seems unlikely to increase the risk of virus' escape from neutralizing antibodies. It was shown that $\Delta \mathrm{H} 69 / \Delta \mathrm{V} 70$ either has a similar susceptibility as wild type to the neutralization by convalescent plasma [58, 63], or an enhanced sensitivity to the neutralization by the sera from the participants vaccinated by mRNA-1273 vaccine (Moderna) [64]. However, $\Delta \mathrm{H} 69 / \Delta \mathrm{V} 70$ could lead to the failure in the diagnosis by Thermopath TaqPath assay targeting $S$ gene [55]. The function of mutation of $\mathrm{P} 681 \mathrm{H}$ is unclear but it locates near the furin-cleavage site, which is important for SARS-CoV-2 entry [65]. In addition, the P681H mutation has appeared many times independently and has become dominant in the local epidemic in Hawaii [64].

Table 2. The summary of five notable genetic variants

\begin{tabular}{|c|c|c|c|c|}
\hline Genetic Variant & Alternative name & Country and time initially isolated* & Spreading range & Note \\
\hline$\overline{D 614 G}$ & - & Germany Feb 2020 & Global [35] & $\begin{array}{l}\text { Increased transmission }[42,44] \text {; increased } \\
\text { infectivity }[42,44]\end{array}$ \\
\hline Cluster 5 & - & Denmark Aug 2020 & No & $\begin{array}{l}\text { Transmission between human and mink [49]; } \\
\text { likely extinct [51] }\end{array}$ \\
\hline VOC 202012/01 & B.1.1.7 20I/501Y.V1 & England Sep 2020 & 94 countries reported [56] & Increased transmission [57] \\
\hline 501Y.V2 & B.1.351 20H/501Y.V2 & South Africa Oct 2020 & 48 countries reported $[74]$ & Possible immune escape [75] \\
\hline P.1 & B.1.1.28.1 20J/501Y.V3 VOC202101/02 & Brazil Dec 2020 & 25 countries reported [89] & Unknown \\
\hline
\end{tabular}

* data were retrieved from GISAID 
Table 3. The activities of different vaccines on two genetic variants

\begin{tabular}{|c|c|c|c|c|}
\hline \multirow[t]{2}{*}{ Vaccines } & \multirow[t]{2}{*}{ Type of vaccine } & \multirow[t]{2}{*}{ Supplier } & \multicolumn{2}{|l|}{ Activities on genetic variants } \\
\hline & & & VOC 202012/01 & 501Y.V2 \\
\hline BNT162b2 & mRNA & Pfizer-BioNTech & Equivalent to wild type strain*[69] & Two - third reduction*[84] \\
\hline mRNA-1273 & mRNA & Moderna & 2-fold reduction compared to D614G strain*[64] & 6-fold reduction*[70] \\
\hline NVX-CoV2373 & Protein nanoparticle & Novavax & $\begin{array}{l}85.6 \% \text { efficacy in Phase } 3 \text { clinical trial [71]; 2-fold } \\
\text { reduction compared to D614G strain*[64] }\end{array}$ & $60 \%$ efficacy in Phase $2 \mathrm{~b}$ clinical trial[71] \\
\hline BBIBP & Inactivated & Sinopharm & No data & 1.6-fold reduction compared to D164G strain*[86] \\
\hline ZF2001 & Recombinant dimeric RBD & Anhui Zhifei Longcom & No data & 1.6-fold reduction compared to D164G strain*[86] \\
\hline
\end{tabular}

VOC 202012/01 is highly transmissible compared to the parental strain of D614G. Using a mathematical model, it was found that VOC 202012/01 is 56\% more transmissible than other preexisting variants of SARS-CoV-2 [65], which might be the reason that had promoted the further national lockdown of UK. Another study predicted the $R_{0}$ of VOC 202012/01 is 1.75 times higher than the ancestral N501 strain, resulting in 75\% more transmission [57]. There is no any evidence demonstrating either the increased or decreased clinical severity of illness caused by VOC 2020/01 in the initial investigation [65]. However, it is claimed recently that a possible increased death rate might associate with VOC 202012/01 [66]. The detailed information on this study is waiting to be disclosed [66].

It seems that variant VOC 202012/01 does not compromise the neutralization by antibodies elicited by previous infection or vaccination [64, 67-72]. Mutation in N501 was previously shown to have modest effects on binding by some monoclonal antibodies but not by convalescent sera [67, 68, 73]. Recently, Xie et al generated isogenic N501 and N501Y SARS-CoV-2 strains, and examined sera from participants vaccinated by mRNA-based COVID-19 vaccine BNT162b2 (Pfizer-BioNTech). They showed that the sera had equivalent neutralizing titers to the N501 and N501Y viruses [72]. A similar study was conducted to examine the neutralization of SARS-CoV-2 pseudoviruses bearing either the Wuhan reference strain or the VOC 202012/01 by sera from participants vaccinated by BNT162b2. They found that the immune sera had equivalent neutralizing titer to both variants (Table 3) [69]. Similarly, with a lentivirus-based pseudovirus assay, sera from recipients of either mRNA-1273 (Moderna) or protein nanoparticle NVX-CoV2373 (Novavax) vaccine were still able to neutralize VOC 202012/01, albeit at moderately reduced levels ( 2 fold) (Table 3) [64, 70]. Consistently, in a phase 3 trial, the vaccine of NVX-CoV2373 demonstrated $85.6 \%$ protective efficacy against VOC 202012/01 (Table 3) [71].

\section{Y.V2 and P.1}

501Y.V2 (also called B.1.351 or 20H/501Y.V2) is another highly transmissible SARS-CoV-2 variant. It emerged from the first wave of the South African COVID-19 epidemic in the Eastern Cape province in early 2020 (Table 2) [34]. However, it spread so quickly that it had become the predominant virus lineage in the Eastern and Western Cape province by the end of November 2020 [34]. This variant has been detected in 48 countries worldwide by March 2021 [74].

The 501Y.V2 variant is characterized by carrying nine mutations in S protein (L18F, D80A, D215G, R246I, $\Delta 242-244$, K417N, E484K, N501Y, A701V) (Table 1) [75], three of which (K417N, E484K and N501Y) locate in the RBD of the S protein [34]. The mutations of both N501Y and E484K locate in the receptor binding motif (RBM) in the RBD (Fig. 1) [32]. N501Y is also presented in the VOC 202012/01 variant [53]. These two mutations could profoundly affect the binding of the variant to host. Indeed, N501Y has been shown to increase the affinity to hACE2 receptor [60-62]. Different from N501Y and E484K, the mutation of K417 locates outside the RBM. It forms a salt-bridge interaction with N30 of ACE2 [76]. SARS-CoV-2 RBD with a replacement of this residue by a valine failed to participate in ACE2 binding [76]. However, the substitution by an asparagine showed an increase binding to ACE2 [77]. Consistently, preliminary results indicate that $501 Y$. V2 variant may also have an increased transmissibility [78]. However, it is not confirmed yet whether the disease severity caused by 501Y. V2 variant is also changed [78].

Nevertheless, the extensive mutations occur in the RBD of 501Y.V2 attracted serious concerns on the potential escape from the antibodies against parental SARS-CoV-2. Indeed, a single mutation in reside 484 was previously shown to significantly reduce the neutralization by several monoclonal antibodies and sera $[73,79]$. Wibmer et al., recently used three classes of therapeutically relevant monoclonal antibodies to examine their neutralizations on 501Y.V2 [75]. Both class 1 and class 2 antibodies target site 1 epitopes that overlap with the ACE2 receptor binding site [80, 81]. Class 1 antibodies are accessible to the RBD "up" conformation while class 2 antibodies can bind both "up" and "down" conformation of S protein. Class 3 antibodies target other regions that are outside the 
ACE2-binding site [81]. The results showed that 501Y.V2 completely escaped from all these three classes of monoclonal antibodies [75]. Furthermore, when plasma from individuals previously infected with SARS-CoV-2 was used, 501Y.V2 demonstrated significantly resistance [75]. Similarly, Cele et al. examined the neutralization of convalescent plasma from patients infected by SARS-CoV-2 carrying D614G mutation but no mutation in RBD or NTD (Fig. 1). They found that the neutralization ability of sera to 501Y.V2 was significantly reduced [82]. The conclusion of 501Y.V2 resistance to multiple classes of SARS-CoV-2 directed monoclonal antibodies and plasma was also reinforced by other groups [75].

Plasma collected from individuals vaccinated by Moderna and Pfizer-BioNTech vaccines were also examined against variants bearing mutations observed in 501Y.V2. The results showed that the neutralization activities of plasma from vaccinated individual to the pseudoviruses expressing N501Y, E484K or K417N:E484K:N510Y were significantly reduced [83]. A preliminary study observed a two third weaker of the neutralizing activity by the BNT162b2-elicited serum against the pseudovirus that bears all mutations in $S$ protein observed in 501Y.V2 [84]. However, the neutralization by sera from participants vaccinated with BNT162b2 against N501Y, $\Delta 69 / \Delta 70+N 501 Y+$ D614G and E484K+ N501Y+D614G pseudoviruses only demonstrated small effects of these mutations on neutralization [85]. Furthermore, Moderna has announced that its COVID-19 vaccine retained the neutralizing activity against 501Y.V2 and VOC 202012/01 despite that a six-fold decrease in the neutralizing efficacy was indeed observed (Table 3) [70]. Similarly, the inactivated vaccine BBIBP-CorV and recombinant dimeric RBD vaccine ZF2001 were shown to largely preserve the neutralizing titers against 501Y.V2, with a slight reduction comparing to original strain or D614G strain (Table 3) [86]. The preliminary data published on Novavax website also indicated that their protein-based COVID-19 vaccine candidate NVX-CoV2373 achieved 60\% efficacy against 501Y.V2 in the Phase 2b clinical trial (Table 3) [71]. However, a detailed data is still lacking. Nevertheless, Moderna has announced to prepare an emerging variant booster candidate (mRNA-1237.351) against the 501Y.V2 variant [70].

A similar variant to 501Y.V2 was identified from Brazil, which was named as variant P.1 (descendent of B.1.1.28), 20J/501Y.V3 or VOC202101/02 (Table 2) $[16,87,88]$. It has been detected in 25 countries (Table 2) [89]. P.1 has three mutations in the RBD of $S$ proteins: K417T, E484K and N501Y (Table 1). The variant P.1 and 501Y.V2 seems developed independently [87]. There is no any evidence of changes in transmissibility, severity, immunity, vaccination and diagnostic [78]. However, genetic variant P.1 and 501Y.V2 are considered to bear similar functional characteristics because the mutations in the RBD of $S$ protein occur at the same sites. Therefore, vaccine efficacy might also be compromised against P.1 if they failed on 501Y.V2.

\section{Variants with mutations in $\mathbf{N}$-terminal domain of $\mathbf{S}$ protein}

Neutralizing antibodies against SARS-CoV-2 mainly target RBD of the $S$ protein which binds to hACE2 [80]. hACE2 is the well-known receptor for SARS-CoV-2. However, the expression level of hACE2 is extremely low in many human tissues, such as in the respiratory tract. It was shown that cells with low expression of ACE2 or without ACE2 expression could be infected by SARS-CoV-2 [90]. These observations suggest that alternative receptor(s) for SARS-CoV-2 binding might exist. Through screening the lung cDNA library, Soh et al. found two receptors (L-SIGN and DC-SIGN) that specifically bind NTD [91]. Additionally, a new potent receptor of the tyrosine-protein kinase receptor UFO (AXL) was identified by another group to bind NTD [92]. It was shown that overexpression of AXL in HEK293T cells promoted SARS-CoV-2 entry in a similar efficiency as those overexpressing ACE2. In contrast, knocking out AXL significantly reduces SARS-CoV-2 infection in pulmonary cells and lung epithelial cells [92]. Importantly, AXL expresses in nearly all human organs, and a correlation of virus infection titers and AXL expression level in patients' samples was observed [92].

The finding of NTD as a binding site for human receptor AXL indicates its clinical significance. Indeed, antibodies targeting NTD can have the neutralizing ability $[93,94]$. Another evidence of the importance of NTD is the mass mutation observed from the genome sequences of SARS-CoV-2 isolates. Through analyzed 146,795 SARS-CoV-2 genome sequences, McCarthy et al. found that the deletions frequently occurred at four sites that defined antigenic site in the NTD of the S protein [95]. Similar observation was reported by McCallum and colleagues, who also identified a vulnerability site containing three regions that can be easily mutated to escape the neutralizing stress in NTD [96].

Except D614G, all the critical variants we reviewed here contain mutations in NTD: for example, L18F in variant 501.V2 and P.1, T20N and P26N in variant P.1, $\Delta \mathrm{H} 69 / \Delta \mathrm{V} 70$ in Cluster 5 and VOC 202012/01, Y144 deletion in VOC 202012/01, 242-244 deletion and R246I in VOC 202012/01. The 
detail mutations in different variants can be seen in Table 1. Therefore, consideration should be given to the mutations in NTD when we evaluate the antibody neutralization abilities.

\section{Conclusive remarks}

SARS-CoV-2 is continuing to threaten human lives one year after the outbreak. Despite a great many vaccines have been developed or being under development, the emergence and quick spread of genetic variants with high transmission ability suggest that the current controlling measures may be invaded (Table 3). Furthermore, the fast-spreading of the SARS-CoV-2 variants may evade immune responses of recovered patients and undermine the vaccines being approved or under development. All countries should collaborate and work together to prevent the spreading of such variants. Research should be conducted to investigate the impact of these variants on vaccination, and new vaccines targeting the important new variant (such as 501Y.V2) should at least be technically prepared immediately.

\section{Acknowledgements}

We acknowledge the Research Committee of the University of Macau (Grant No.: MYRG2019-000050-FHS) and the Macau Science and Technology Development Fund (Grant No.: FDCT/0058/2018/A2 and FDCT/0113/2019/A2) for providing financial support for this research.

\section{Competing Interests}

The authors have declared that no competing interest exists.

\section{References}

1. Zheng J. SARS-CoV-2: an emerging coronavirus that causes a global threat. Int J Biol Sci. 2020; 16: 1678-85.

2. Zhu N, Zhang D, Wang W, Li X, Yang B, Song J, et al. A novel coronavirus from patients with pneumonia in China, 2019. N Engl J Med. 2020; 382: 727-33.

3. Zhao X, Ma X, Wang W, Niu P, Xu W, Gao G, et al. A novel coronavirus genome identified in a cluster of pneumonia cases - Wuhan, China 2019-2020. China CDC Weekly. 2020; 2: 61-2

4. Wang C, Horby PW, Hayden FG, Gao GF. A novel coronavirus outbreak of global health concern. Lancet. 2020; 395: 470-3.

5. Hu B, Guo H, Zhou P, Shi ZL. Characteristics of SARS-CoV-2 and COVID-19. Nat Rev Microbiol. 2020; 19(3):141-154.

6. [Internet] World Health Organization. Weekly epidemiological update - 27 January 2021. https://www.who.int/publications/m/item/weeklyepidemiological-update-27-january-2021. (Accessed on 1 Feb 2021).

7. [Internet] U.S. Food\& Drug Administration. FDA approves first treatment for COVID-19. https://www.fda.gov/news-events/press-announcements/fdaapproves-first-treatment-covid-19. (Accessed on $1 \mathrm{Feb} 2021$ )

8. Li Z, Wang X, Cao D, Sun R, Li C, Li G. Rapid review for the anti-coronavirus effect of remdesivir. Drug Discov Ther. 2020; 14: 73-6.

9. Beigel JH, Tomashek KM, Dodd LE, Mehta AK, Zingman BS, Kalil AC, et al. Remdesivir for the treatment of Covid-19 - Final report. N Engl J Med. 2020; 383: 1813-26.

10. [Internet] Zimmer C, Corum J, Wee S-L. Coronavirus vaccine tracker. https://www.nytimes.com/interactive/2020/science/coronavirus-vaccine-tr acker.html. (Accessed on 1 Feb 2021).

11. Gaebler C, Nussenzweig MC. All eyes on a hurdle race for a SARS-CoV-2 vaccine. Nature. 2020; 586: 501-2.

12. Krammer F. SARS-CoV-2 vaccines in development. Nature. 2020; 586: 516-27.
13. Denison MR, Graham RL, Donaldson EF, Eckerle LD, Baric RS Coronaviruses: an RNA proofreading machine regulates replication fidelity and diversity. RNA Biol. 2011; 8: 270-9.

14. Graham RL, Becker MM, Eckerle LD, Bolles M, Denison MR, Baric RS. A live, impaired-fidelity coronavirus vaccine protects in an aged, immunocompromised mouse model of lethal disease. Nat Med. 2012; 18: 1820-6.

15. Fauver JR, Petrone ME, Hodcroft EB, Shioda K, Ehrlich HY, Watts AG, et al. Coast-to-Coast spread of SARS-CoV-2 during the early epidemic in the United States. Cell. 2020; 181: 990-6 e5.

16. [Internet] Centers for Disease Control and Prevention. Emerging SARS-CoV-2 variants. https://www.cdc.gov/coronavirus/2019-ncov/more/science-andresearch/scientific-brief-emerging-variants.html. (Accessed on 1 Feb 2021).

17. Callaway E. 'A bloody mess': Confusion reigns over naming of new COVID variants. Nature. 2021; 589: 339.

18. Callaway E. Could new COVID variants undermine vaccines? Labs scramble to find out. Nature. 2021; 589: 177-8.

19. Callaway E. Fast-spreading COVID variant can elude immune responses. Nature. 2021; 589(7843):500-501

20. Dai L, Gao GF. Viral targets for vaccines against COVID-19. Nat Rev Immunol. 2021; 21: 73-82

21. Lu R, Zhao X, Li J, Niu P, Yang B, Wu H, et al. Genomic characterisation and epidemiology of 2019 novel coronavirus: implications for virus origins and receptor binding. Lancet. 2020; 395: 565-74.

22. Zhong NS, Zheng BJ, Li YM, et al. Epidemiology and cause of severe acute respiratory syndrome (SARS) in Guangdong, People's Republic of China, in February, 2003. Lancet. 2003; 362: 1353-8.

23. Drosten C, Gunther S, Preiser W, van der Werf S, Brodt HR, Becker S, et al. Identification of a novel coronavirus in patients with severe acute respiratory syndrome. N Engl J Med. 2003; 348: 1967-76.

24. Zaki AM, van Boheemen $S$, Bestebroer TM, Osterhaus $A D$, Fouchier RA. Isolation of a novel coronavirus from a man with pneumonia in Saudi Arabia. N Engl J Med. 2012; 367: 1814-20.

25. Wu A, Peng Y, Huang B, Ding X, Wang X, Niu P, et al. Genome composition and divergence of the novel coronavirus (2019-nCoV) originating in China. Cell Host Microbe. 2020; 27: 325-8

26. Zhou $P$, Yang $X L$, Wang XG, Hu B, Zhang $L$, Zhang $W$, et al. A pneumonia outbreak associated with a new coronavirus of probable bat origin. Nature. 2020; 579: 270-3

27. Wang Q, Zhang $\mathrm{Y}$, Wu L, Niu S, Song C, Zhang Z, et al. Structural and functional basis of SARS-CoV-2 entry by using human ACE2. Cell. 2020; 181: $894-904$ e9.

28. Ou X, Liu Y, Lei X, Li P, Mi D, Ren L, et al. Characterization of spike glycoprotein of SARS-CoV-2 on virus entry and its immune cross-reactivity with SARS-CoV. Nat Commun. 2020; 11: 1620.

29. Harrison AG, Lin T, Wang P. Mechanisms of SARS-CoV-2 transmission and pathogenesis. Trends Immunol. 2020; 41: 1100-15.

30. Hoffmann M, Kleine-Weber H, Pöhlmann S. A multibasic cleavage site in the spike protein of SARS-CoV-2 is essential for infection of human lung cells. Mol Cell. 2020; 78: 779-84.e5.

31. Shulla A, Heald-Sargent T, Subramanya G, Zhao J, Perlman S, Gallagher T. A transmembrane serine protease is linked to the severe acute respiratory syndrome coronavirus receptor and activates virus entry. J Virol. 2011; 85: 873-82.

32. Walls AC, Park YJ, Tortorici MA, Wall A, McGuire AT, Veesler D. Structure, function, and antigenicity of the SARS-CoV-2 spike glycoprotein. Cell. 2020; 181: 281-92.e6

33. Huang $\mathrm{Y}$, Yang $\mathrm{C}, \mathrm{Xu} \mathrm{XF}, \mathrm{Xu} \mathrm{W}$, Liu SW. Structural and functional properties of SARS-CoV-2 spike protein: potential antivirus drug development for COVID-19. Acta Pharmacol Sin. 2020; 41: 1141-9.

34. Tegally H, Wilkinson E, Giovanetti M, Iranzadeh A, Fonseca V, Giandhari J, et al. Emergence and rapid spread of a new severe acute respiratory syndrome-related coronavirus 2 (SARS-CoV-2) lineage with multiple spike mutations in South Africa. medRxiv. 2020: doi: 10.1101/2020.12.21.20248640. [Epub ahead of print].

35. Korber B, Fischer WM, Gnanakaran S, Yoon $\mathrm{H}$, Theiler J, Abfalterer W, et al. Tracking changes in SARS-CoV-2 spike: Evidence that D614G increases infectivity of the COVID-19 virus. Cell. 2020; 182: 812-27 e19.

36. Laha S, Chakraborty J, Das S, Manna SK, Biswas S, Chatterjee R Characterizations of SARS-CoV-2 mutational profile, spike protein stability and viral transmission. Infect Genet Evol. 2020; 85: 104445.

37. Watanabe Y, Berndsen ZT, Raghwani J, Seabright GE, Allen JD, Pybus OG, et al. Vulnerabilities in coronavirus glycan shields despite extensive glycosylation. Nat Commun. 2020; 11: 2688.

38. Morais IJ, Polveiro RC, Souza GM, Bortolin DI, Sassaki FT, Lima ATM. The global population of SARS-CoV-2 is composed of six major subtypes. Sci Rep. 2020; 10: 18289.

39. Volz E, Hill V, McCrone JT, Price A, Jorgensen D, O'Toole A, et al. Evaluating the effects of SARS-CoV-2 spike mutation D614G on transmissibility and pathogenicity. Cell. 2021; 184: 64-75 e11.

40. Lorenzo-Redondo R, Nam HH, Roberts SC, Simons LM, Jennings LJ, Qi C, et al. A clade of SARS-CoV-2 viruses associated with lower viral loads in patient upper airways. EBioMedicine. 2020; 62: 103112. 
41. Yurkovetskiy L, Wang X, Pascal KE, Tomkins-Tinch C, Nyalile TP, Wang Y, et al. Structural and functional analysis of the D614G SARS-CoV-2 spike protein variant. Cell. 2020; 183: 739-51 e8.

42. Plante JA, Liu Y, Liu J, Xia H, Johnson BA, Lokugamage KG, et al. Spike mutation D614G alters SARS-CoV-2 fitness. Nature. 2020: doi: 10.1038/s41586-020-2895-3. [Epub ahead of print].

43. Zhang L, Jackson CB, Mou H, Ojha A, Peng H, Quinlan BD, et al. SARS-CoV-2 spike-protein D614G mutation increases virion spike density and infectivity. Nat Commun. 2020; 11: 6013.

44. Hou YJ, Chiba S, Halfmann P, Ehre C, Kuroda M, Dinnon KH, 3rd, et al. SARS-CoV-2 D614G variant exhibits efficient replication ex vivo and transmission in vivo. Science. 2020; 370: 1464-8.

45. van Dorp L, Richard D, Tan CCS, Shaw LP, Acman M, Balloux F. No evidence for increased transmissibility from recurrent mutations in SARS-CoV-2. Nat Commun. 2020; 11: 5986.

46. Zhou B, Thao TTN, Hoffmann D, Taddeo A, Ebert N, Labroussaa F, et al. SARS-CoV-2 spike D614G variant confers enhanced replication and transmissibility. bioRxiv. 2020: doi: 10.1101/2020.10.27.357558.

47. Weissman D, Alameh MG, de Silva T, Collini P, Hornsby H, Brown R, et al. D614G spike mutation increases SARS CoV-2 susceptibility to neutralization. Cell Host Microbe. 2021; 29: 23-31 e4.

48. Cashman DP. Dominance of SARS-CoV-2 D614G variant explained by the requirement of COVID-19 for calcium; proximate therapeutic implication(s) for COVID-19. . J Clin Immunol Immunother. 2020; 6: 048.

49. [Internet] Ria Lassaunière JF, Morten R, Ander F, Charlotta PS, Thomas BR, Anette B, Anders F. SARS-CoV-2 spike mutations arising in Danish mink and their spread to humans. https://files.ssi.dk/Mink-cluster-5-short-report_ $\mathrm{AFO} 2$.

50. Bazykin GA SO, Danilenko D, Fadeev A, Komissarova K, Ivanova A, Sergeeva M, Safina K, Nabieva E, Klink G, Garushyants S, Zabutova J, Kholodnaia A, Skorokhod I, Ryabchikova VV, Komissarov A, Lioznov D. Emergence of $\mathrm{Y} 453 \mathrm{~F}$ and $\triangle 69-70 \mathrm{HV}$ mutations in a lymphoma patient with long-term COVID-19. https://virological.org/t/emergence-of-y453f-and-69-70hvmutations-in-a-lymphoma-patient-with-long-term-covid-19/580. (Accessed on $1 \mathrm{Feb} 2021$ ).

51. Krause TG. Den seneste udvikling af covid-19 på minkfarme og blandt mennesker. Status uge 47. https://www.ssi.dk/aktuelt/nyheder/2020/denseneste-udvikling-af-covid-19-pa-minkfarme-og-blandt-mennesker-status-uge -47. (Accessed on 1 Feb 2021)

52. Oude Munnink BB, Sikkema RS, Nieuwenhuijse DF, Molenaar RJ, Munger E, Molenkamp R, et al. Transmission of SARS-CoV-2 on mink farms between humans and mink and back to humans. Science. 2021; 371: 172-7.

53. Tang JW, Tambyah PA, Hui DS. Emergence of a new SARS-CoV-2 variant in the UK. J Infect. 2020: doi: 10.1016/j.jinf.2020.12.024. [Epub ahead of print]

54. [Internet] Preliminary genomic characterisation of an emergent SARS-CoV-2 lineage in the UK defined by a novel set of spike mutations. https://virological.org/t/preliminary-genomic-characterisation-of-an-emerg ent-sars-cov-2-lineage-in-the-uk-defined-by-a-novel-set-of-spike-mutations/5 63. (Accessed on 1 Feb 2021)

55. [Internet] Investigation of novel SARS-CoV-2 variant - Variant of Concern 202012/01 technical briefing 2. https://assets.publishing.service.gov.uk/ government/uploads/system/uploads/attachment_data/file/949639/Techn ical_Briefing_VOC202012-2_Briefing_2_FINAL.pdf. (Accessed on 1 Feb 2021).

56. O'Toole Á, Hill V. Global report investigating novel coronavirus haplotypes B.1.1.7 https://cov-lineages.org/global_report_B.1.1.7.html (Accessed on 2 Mar 2021).

57. Leung K, Shum MH, Leung GM, Lam TT, Wu JT. Early transmissibility assessment of the N501Y mutant strains of SARS-CoV-2 in the United Kingdom, October to November 2020. Euro Surveill. 2021; 26.

58. Kemp S, Meng B, Ferriera I, Datir R, Harvey W, Collier D, et al. Recurrent emergence and transmission of a SARS-CoV-2 Spike deletion H69/V70. bioRxiv. 2021: doi:10.1101/2020.12.14.422555. [Epub ahead of print].

59. Wan Y, Shang J, Graham R, Baric RS, Li F. Receptor recognition by the novel coronavirus from Wuhan: an analysis based on decade-long structural studies of SARS Coronavirus. J Virol. 2020; 94.

60. Starr TN, Greaney AJ, Hilton SK, Ellis D, Crawford KHD, Dingens AS, et al. Deep mutational scanning of SARS-CoV-2 receptor binding domain reveals constraints on folding and ACE2 binding. Cell. 2020; 182: 1295-310 e20.

61. Mathavan S, Kumar S. Evaluation of the effect of D614G, N501Y and S477N mutation in Sars-Cov-2 through computational approach. Preprints.org; 2020: doi: 10.20944. [Epub ahead of print].

62. Tian F, Tong B, Sun L, Shi S, Zheng B, Wang Z, et al. Mutation N501Y in RBD of spike protein strengthens the interaction between COVID-19 and its receptor ACE2. bioRxiv. 2021: doi: 10.1101/2021.02.14.431117. [Epub ahead of print].

63. Kemp SA, Collier DA, Datir RP, Ferreira I, Gayed S, Jahun A, et al. SARS-CoV-2 evolution during treatment of chronic infection. Nature. 2021: doi: 10.1038/s41586-021-03291-y. [Epub ahead of print]

64. Shen X, Tang H, McDanal C, Wagh K, Fischer W, Theiler J, et al. SARS-CoV-2 variant B.1.1.7 is susceptible to neutralizing antibodies elicited by ancestral Spike vaccines. bioRxiv. 2021: doi: 10.1101/2021.01.27.428516. [Epub ahead of print].

65. Davies NG, Barnard RC, Jarvis CI, Kucharski AJ, Munday J, Pearson CAB, et al. Estimated transmissibility and severity of novel SARS-CoV-2 Variant of
Concern 202012/01 in England medRxiv 2020: doi: 10.1101/2020.12.24.20248822. [Epub ahead of print].

66. Iacobucci G. Covid-19: New UK variant may be linked to increased death rate, early data indicate. BMJ. 2021; 372: n230.

67. Greaney AJ, Starr TN, Gilchuk P, Zost SJ, Binshtein E, Loes AN, et al. Complete mapping of mutations to the SARS-CoV-2 spike receptor-binding domain that escape antibody recognition. Cell Host Microbe. 2021; 29: 44-57 e9.

68. Starr TN, Greaney AJ, Addetia A, Hannon WW, Choudhary MC, Dingens AS, et al. Prospective mapping of viral mutations that escape antibodies used to treat COVID-19. Science. 2021: eabf9302.

69. Muik A, Wallisch A-K, Sänger B, Swanson KA, Mühl J, Chen W, et al. Neutralization of SARS-CoV-2 lineage B.1.1.7 pseudovirus by BNT162b2 vaccine-elicited human sera. bioRxiv. 2021: doi: 10.1101/2021.01.18.426984. [Epub ahead of print].

70. [Internet] Moderna COVID-19 vaccine retains neutralizing activity against emerging variants first identified in the U.K. and the Republic of South Africa. https://investors.modernatx.com/news-releases/news-release-details/mode rna-covid-19-vaccine-retains-neutralizing-activity-against (Accessed on $1 \mathrm{Feb}$ 2021).

71. [Internet] Novavax COVID-19 vaccine demonstrates $89.3 \%$ efficacy in UK phase 3 trial. https://ir.novavax.com/news-releases/news-release-details/ novavax-covid-19-vaccine-demonstrates-893-efficacy-uk-phase-3. (Accessed on 1 Feb 2021)

72. Xie X, Zou J, Fontes-Garfias CR, Xia H, Swanson KA, Cutler $M$, et al. Neutralization of N501Y mutant SARS-CoV-2 by BNT162b2 vaccine-elicited sera. bioRxiv. 2021: doi: 10.1101/2021.01.07.425740. [Epub ahead of print].

73. Greaney AJ, Loes AN, Crawford KHD, Starr TN, Malone KD, Chu HY, et al. Comprehensive mapping of mutations in the SARS-CoV-2 receptor-binding domain that affect recognition by polyclonal human plasma antibodies. Cell Host \& Microbe. 2021: doi: 10.1016/j.chom.2021.02.003. [Epub ahead of print].

74. O'Toole Á, Hill V. Global report investigating novel coronavirus haplotypes B.1.351 https://cov-lineages.org/global_report_B.1.351.html (Accessed on 2 Mar 2021).

75. Wibmer CK, Ayres F, Hermanus T, Madzivhandila M, Kgagudi P, Lambson $\mathrm{BE}$, et al. SARS-CoV-2 501Y.V2 escapes neutralization by South African COVID-19 donor plasma. bioRxiv. 2021: doi: 10.1101/2021.01.18.427166. [Epub ahead of print].

76. Lan J, Ge J, Yu J, Shan S, Zhou H, Fan S, et al. Structure of the SARS-CoV-2 spike receptor-binding domain bound to the ACE2 receptor. Nature. 2020; 581 : 215-20.

77. Fratev F. The N501Y and K417N mutations in the spike protein of SARS-CoV-2 alter the interactions with both hACE2 and human derived antibody: A Free energy of perturbation study. bioRxiv. 2020: doi: 10.1101/2020.12.23.424283. [Epub ahead of print].

78. [Internet] European Centre for Disease Prevention and Control. Risk related to the spread of new SARS-CoV-2 variants of concern in the EU/EEA - first update https://www ecdceuropa.eu/sites/default/files/documents/ COVID-19-risk-related-to-spread-of-new-SARS-CoV-2-variants-EU-EEA-firstupdate.pdf (Accessed on 1 Feb 2021).

79. Weisblum Y, Schmidt F, Zhang F, DaSilva J, Poston D, Lorenzi JC, et al. Escape from neutralizing antibodies by SARS-CoV-2 spike protein variants. Elife. 2020; 9 .

80. Piccoli L, Park YJ, Tortorici MA, Czudnochowski N, Walls AC, Beltramello M, et al. Mapping neutralizing and immunodominant sites on the SARS-CoV-2 spike receptor-binding domain by structure-guided high-resolution serology. Cell. 2020; 183: 1024-42 e21.

81. Barnes CO, Jette CA, Abernathy ME, Dam KA, Esswein SR, Gristick HB, et al. SARS-CoV-2 neutralizing antibody structures inform therapeutic strategies. Nature. 2020; 588: 682-7.

82. Cele S, Gazy I, Jackson L, Hwa S-H, Tegally H, Lustig G, et al. Escape of SARS-CoV-2 501Y.V2 variants from neutralization by convalescent plasma. medRxiv. 2021: doi: 10.1101/2021.01.26.21250224. [Epub ahead of print].

83. Wang Z, Schmidt F, Weisblum Y, Muecksch F, Barnes CO, Finkin S, et al. mRNA vaccine-elicited antibodies to SARS-CoV-2 and circulating variants. bioRxiv. 2021: doi: 10.1101/2021.01.15.426911. [Epub ahead of print]

84. Liu Y, Liu J, Xia H, Zhang X, Fontes-Garfias CR, Swanson KA, et al. Neutralizing activity of BNT162b2-elicited serum - Preliminary report. N Engl J Med. 2021: doi: 10.1056/NEJMc2102017. [Epub ahead of print].

85. Xie X, Liu Y, Liu J, Zhang X, Zou J, Fontes-Garfias CR, et al. Neutralization of SARS-CoV-2 spike 69/70 deletion, E484K and N501Y variants by BNT162b2 vaccine-elicited sera. Nat Med. 2021: doi: 10.1038/s41591-021-01270-4. [Epub ahead of print].

86. Huang B, Dai L, Wang H, Hu Z, Tan W, Gao GF, et al. Neutralization of SARS-CoV-2 VOC 501Y.V2 by human antisera elicited by both inactivated BBIBP-CorV and recombinant dimeric RBD ZF2001 vaccines. bioRxiv. 2021: doi:10.1101/2021.02.01.429069. [Epub ahead of print]

87. [Internet] Genomic characterisation of an emergent SARS-CoV-2 lineage in Manaus: preliminary findings. https://virological.org/t/genomiccharacterisation-of-an-emergent-sars-cov-2-lineage-in-manaus-preliminary-fi ndings/586. (Accessed on 1 Feb 2021).

88. [Internet] Variants of Concern or under investigation: data up to 3 March 2021 https://www.gov.uk/government/publications/covid-19-variants-genomica lly-confirmed-case-numbers/variants-distribution-of-cases-data (Accessed on 3 Mar 2021) 
89. O'Toole Á, Hill V. Global report investigating neovel coronavirus haplotypes P.1 https://cov-lineages.org/global_report_P.1.html (Accessed on 2 Mar 2021).

90. Bost P, Giladi A, Liu Y, Bendjelal Y, Xu G, David E, et al. Host-viral infection maps reveal signatures of severe COVID-19 patients. Cell. 2020; 181: 1475-88 e12.

91. Soh WT, Liu $Y$, Nakayama EE, Ono $C$, Torii $S$, Nakagami $H$, et al. The $\mathrm{N}$-terminal domain of spike glycoprotein mediates SARS-CoV-2 infection by associating with L-SIGN and DC-SIGN. bioRxiv. 2020: doi: 10.1101/2020.11.05.369264. [Epub ahead of print].

92. Wang S, Qiu Z, Hou Y, Deng X, Xu W, Zheng T, et al. AXL is a candidate receptor for SARS-CoV-2 that promotes infection of pulmonary and bronchial epithelial cells. Cell Res. 2021: 1-15.

93. Chi X, Yan R, Zhang I, Zhang G, Zhang Y, Hao M, et al. A neutralizing human antibody binds to the N-terminal domain of the Spike protein of SARS-CoV-2. Science. 2020; 369: 650-5.

94. Liu L, Wang P, Nair MS, Yu J, Rapp M, Wang O, et al. Potent neutralizing antibodies against multiple epitopes on SARS-CoV-2 spike. Nature. 2020; 584: $450-6$.

95. McCarthy KR, Rennick LJ, Nambulli S, Robinson-McCarthy LR, Bain WG, Haidar G, et al. Natural deletions in the SARS-CoV-2 spike glycoprotein drive antibody escape. bioRxiv. 2020: doi: 10.1101/2020.11.19.389916. [Epub ahead of print].

96. McCallum M, Marco AD, Lempp F, Tortorici MA, Pinto D, Walls AC, et al. $\mathrm{N}$-terminal domain antigenic mapping reveals a site of vulnerability for SARS-CoV-2. bioRxiv. 2021: doi:10.1101/2021.01.14.426475. [Epub ahead of print].

97. Wrobel AG, Benton DJ, Xu P, Roustan C, Martin SR, Rosenthal PB, et al. SARS-CoV-2 and bat RaTG13 spike glycoprotein structures inform on virus evolution and furin-cleavage effects. Nat Struct Mol Biol. 2020; 27: 763-7. 